\title{
A Tribute to Professor Tirtha Nath Barkataky
}

\section{Dr Mahfuza Rahman ${ }^{+}$}

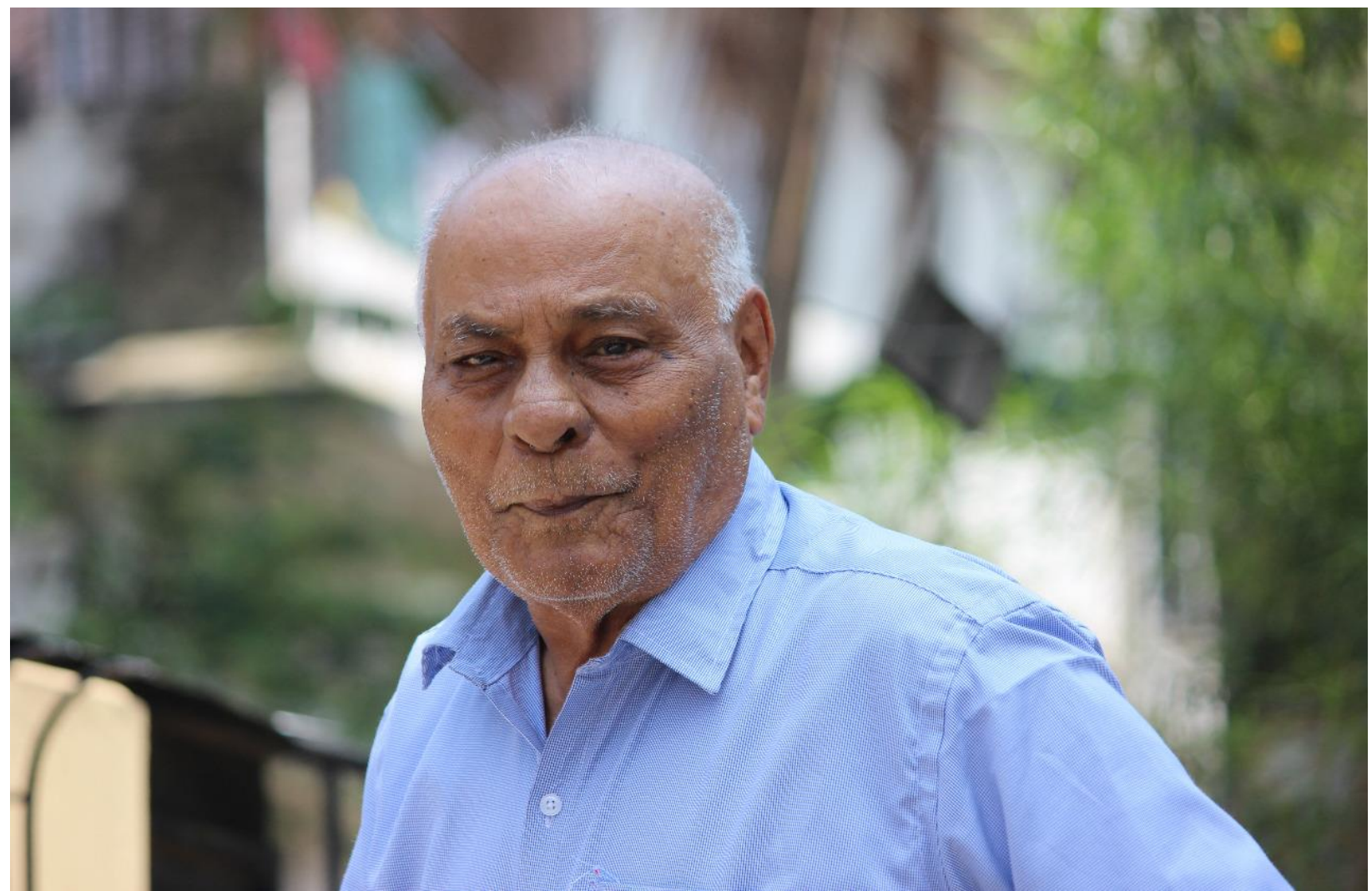

Head, Department of Geography Cotton College from 1959 -1992

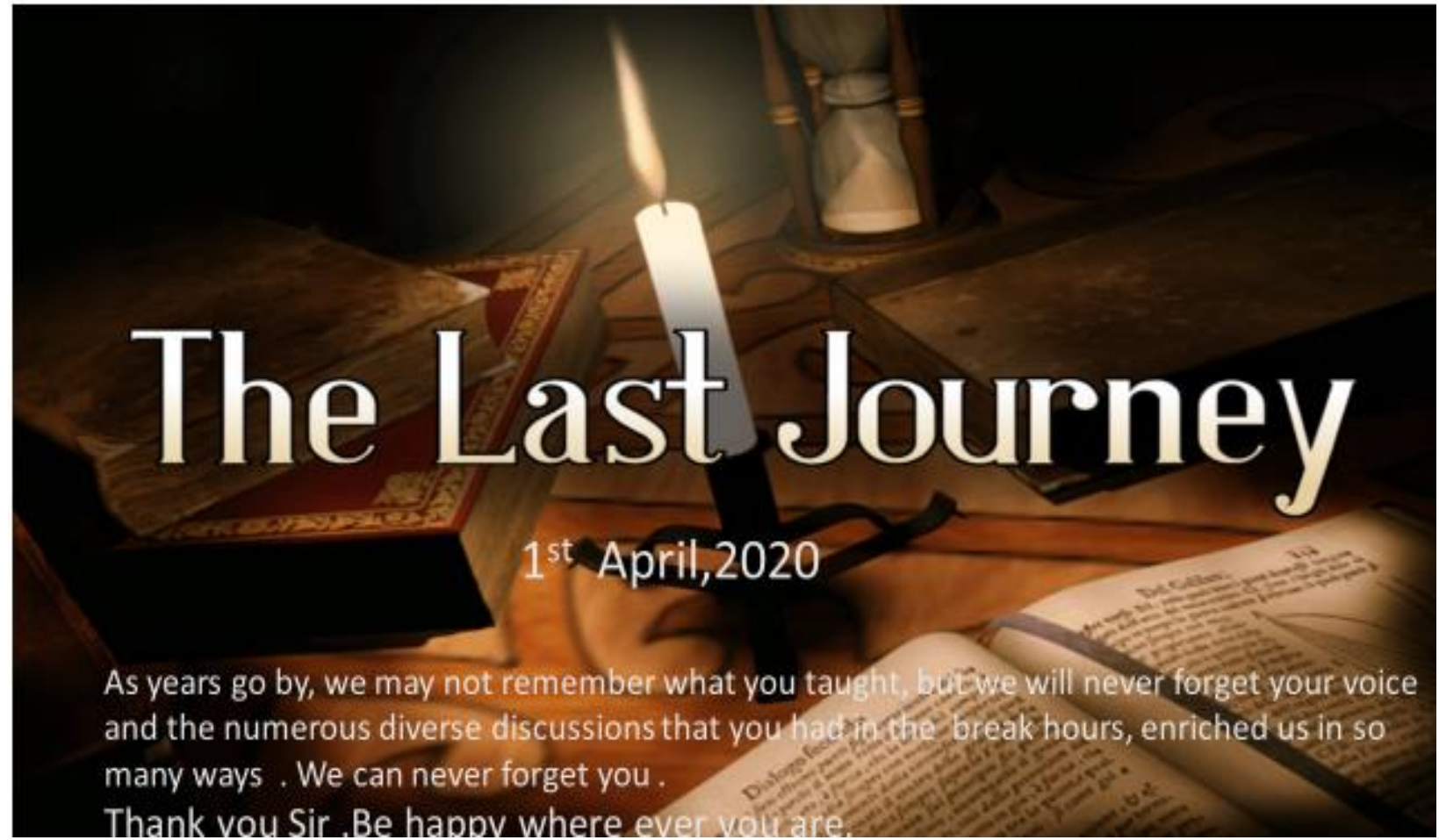

${ }^{\dagger}$ Former Head, Department of Geography, Cotton College (Now University), Email: dr.mahfuzarahman@gmail.com (C) 2020 Rahman. This is an Open Access article distributed under the terms of the Creative Commons Attribution License (http://creativecommons.org/licenses/by/2.0), which permits unrestricted use, distribution, and reproduction in any medium, provided the original work is properly cited. 
It gives me immense solace to offer a tribute to Professor Barkataky Sir.

Late Professor Tritha Nath Barkataky Sir, was born on 24 February 1935 in Amguri, Sibsagar District of Assam. He was the Founder Head of the Geography Department, Cotton College Guwahati (now University).

Sir completed his M.Sc. in Geography from University of Saugar, Sagar, Madhya Pradesh and joined Cotton College on 19 August 1959 and continued as Head of the Department till his retirement on 30th June 1992.

Barkataky Sir, established the department and started initially by teaching Commercial Geography, although that was not his forte, as he specialised in Physical Geography. In 1960, the Geography Department started functioning from the first floor of the Union Hall, (that houses the Auditorium on the ground floor) sharing it with Geology Department, Cotton College (now University). In 1961, Geography Pass Course was introduced, and in 1962, Bachelors in Arts, with Honours in Geography was offered to the students.

Sir had single-handedly developed the Department till Professor Biraj Chowdhury Sir joined in February 1992 followed by Professor Jibon Bhattacharjee Sir joining in March 1962.

Barkataky Sir was academically associated with Pragjyotish College, B Barooah College and Gauhati University.

Besides academics, he was an ardent sports lover. He was the founder Vice President of the Assam Mountaineering Association, and Late Rohini Bhuyan was the President. He was the first Assamese who was trained under Nowang Gombu ( the first man in the world to climb Mt Everest twice) in 1964 for Rock climbing and mountaineering.

I remember so vividly, how enthusiastically he shouldered responsibilities during college week. No sports event would happen, without his presence. This reminds me about the Bordoloi Trophy Football Tournament. Whenever there was a tournament happening in the city, he would watch as many matches as he could, as matches started from $2 \mathrm{pm}$. There was this fatherly figure, yet there was something very childlike about Sir. During one such match, that he was going to witness, he hurriedly carried the cover of an old register book. When asked, why he needs it, his simple answer was 'it will come in handy and protect me from the sun'.

I would also like to mention that besides academics and sports, he was actively associated with the All Assam Students Union, All Assam Gana Sangram Parisad and Sadou Assam Karmachari Parisad during the Assam Movement against foreigners in the 1980s, for which he remained underground for some time.

Many may not know that he was a former Councilor of ward 41, Guwahati Municipal Corporation too.

Professor Barkataky Sir, was addressed by most of his colleagues and contemporary faculty members as 'Dada" or Big Brother.

My rendezvous with Barkataky Sir began in 1971 as a First-year Honours student and later as a colleague until his retirement.

He was a person with sterling human qualities, who had a lively, cheerful, openhearted disposition with ample gentility, love, compassion and generosity. These qualities of his head and heart won him a big following among the students and colleagues. Although in the following decades a series of misfortune had befallen him, including the loss of his only son, Sir could maintain his stoic, calm disposition of mind and exude confidence and positivity in his dealings with others, besides being warm, passionate and courteous.

All his traits attracted colleagues from different departments to come to the Geography Department, which was a storage of information and knowledge, to discuss various issues from politics, culture, society, history, sports, to cuisine, over a hot cup of tea lovingly served by Dhoroni Kai, who was our sincere support staff. We, the younger lot, learnt so many things just 
listening to their discussions, arguments and jokes.

Very rarely did Sir sit in his room. He was most of the time amongst us, in the big-shared room located on the first floor of the main building.

We were witness to numerous discussions, debates, arguments, differences of opinions, all happened, but none took it to heart personally. Out of the room, everything was forgotten.

Sir was a competent leader in real sense. Always calm but plans his next move well in the hour of crisis. He brought in a culture of togetherness, cooperation, sharing and an open environment where each one could laugh and talk freely in the department.

Professor Barkataky Sir's demise on 1 April 2020 has been one of the saddest news, that further deepened the solitude because of the COVID 19 lockdown life. It was more so because of our inability to pay homage during the last rites and meet the aggrieved family members to express our heartfelt condolences.

Sir will be sadly missed and fondly remembered by all of us - his colleagues, students, friends and relations. May his noble soul remain in eternal peace. 